\title{
Study on Ways to Improve the 48 Hours Clause Concerning Work-related Injury
}

\author{
Chengyu Zeng \\ School of Political Science and Public Administration \\ East China University of Political Science and Law \\ Shanghai, China 201620
}

\begin{abstract}
The clause "Dying of sudden diseases within 48 hours is deemed as work-related injury" is defined clearly in the identification of work-related injury in China, though it plays an active role to some degree in protecting the rights and interests of laborers, yet there are still lots of disadvantages existing in practice, which is urgent for improvement. Considering the frequent death from overwork occurring in recent years, the article, based on cases, analyzes problems existing in the clause and suggests that the work factor should be emphasized in the identification of work-related injury and a legal concept of death from overwork shall be established initially to solve the dispute over the 48 hours clause, based on the analysis, the overwork death is finally incorporated into the work injury system so as to improve the identification standard and solve the difficulty of the time.
\end{abstract}

Keywords-identification of work-related injury; 48 hours; work-related reasons; death from overwork

\section{INTRODUCTION}

The clause "Dying of sudden diseases within 48 hours is deemed as work-related injury" is defined clearly in the identification of work-related injury in China, which however is doubted by scholars at the beginning, especially in recent years, the cases of Liu Hai ${ }^{1}$, Zhang Zhijuan ${ }^{2}$ and Xu Dayong ${ }^{3}$

${ }^{1}$ Liu Hai, engineer in a Shenzhen-stationed company, suffered from a sudden disease in the company but died after rescuing for 77 hours, within three months before death his overwork time were $93,82.5$ and 128 hours respectively. According to the rescue time which exceeded 48 hours, Shenzhen Human Resources and Social Security Administration identified it as non-work-related injury.

Yan Zhaoxiong, engineer, suffered from heart attack at work, the rescue time reached 77 hours, he was not identified as work-related injury [EB/OB] Shenzhen Evening News

http://news.sina.com.cn/s/2011-03-25/170322181896.shtml 2011-3-25/20168-20

${ }^{2}$ Zhang Zhijuan, street cleaner, working overtime often in 20 years, Harbin. After working 4 hours before dawn on Feb 14, she started an 8-hour work from the morning, when working, she suffered from a sudden cerebral hemorrhage and became a gork after rescue. Surprisingly her employer said: it's not deemed as work-related injury for she's alive as provide in the law. A model street cleaner suffering a disease at work has no money for treatment, the employer said: it's not deemed as work-related injury for she's alive [EB/OL] Yangcheng Evening News

http://www.ycwb.com/ePaper/ycwb/html/2012-05/17/content_1392947.html 2012-5-17/2016-8-20

${ }^{3} \mathrm{Xu}$ Dayong, an employee in a company, Jiangsu province, worked in the burning sun during Jul 16-18 and were on duty for two nights. In the have caused lots of doubts to the nature of the 48 hours clause and even the legislative thought of identification the workrelated injury in the country. What are basic principles for the identification of work-related injury? Why is the work-related reason, a fundamental element, ignored in the 48 hours clause but with other factors regarded as rescue time, disease time, place, death or not? The clause is extremely formalist without flexibility, and is the rule unbending or the system improperly designed? The article will dissect the problems existing in the 38 hours clause, and study ways for improvement.

\section{SOURCES OF LEGISLATION FOR THE 48 HOURS ClAUSE}

According to Article 15 of the Regulations on WorkRelated Injury Insurance, it is stipulated that "it shall be deemed as work-related injury if employees have died of sudden illness or died after rescue efforts that proved ineffective within 48 hours", namely the work-related injury can be identified with three necessary conditions namely work time, post and dying of sudden diseases or dying after rescue efforts that prove ineffective within 48 hours. According to Article 3 of the Opinions on Several Issues concerning the Implementation of the Regulation on Work-related Injury Insurances issued by of the Ministry of Labor and Social Security in 2004, it is stipulated that "the "outburst of a disease" shall include all kinds of diseases. The starting time for computation of the "48 hours" after the outburst of the disease shall be the time of the first diagnosis by a medical institution".

The clause of 48 hours is originated from Item 4 of Article 8 of the Interim Measures for Work-Related Insurance of Enterprise Staffs issued by the former Ministry of Labor in 1996, it is stipulated that "Within the time and area for production and work, if the employee dies of intense work or

afternoon of Jul 18, he felt uncomfortable and got off work at 19 p.m. In the early morning, his disease worsened and died in the morning of Jul 19 after rescue in a hospital. He was diagnosed with brainstem hemorrhage, yet the labor department considered that Xu Dayong suffered from a sudden disease at home, which was inconformity with the identification of work-related injury "disease at work and work place", so it was not deemed as workrelated injury.

Wang Chengyu and Li Linqing, Conditions and Identification for Death Deemed as Work-Related Injury [EB/OL] People's Court Daily (Vision VII) http://www.chinacourt.org/article/detail/2015/03/id/1573875.shtml 2015-326/2016-8-20 
sudden diseases or is in total disability after the first rescue and treatment, it shall be deemed as work-related injury". The "intense work" is hard for quantification, difficult for operation in practice, which go against the improvement of production efficiency, so it was deleted by the former Ministry of Labor. However, the sudden diseases occurring at the work time, work post but by non-work factors were deemed as workrelated injury, which increased the burden of the employers. In order to ensure the rational distribution of rights and interests between laborer and employee, the labor department restricted the rescue time to be 48 hours.

\section{PROBlems EXISTING IN THE 48 Hours Clause}

In order to protect the rights and interests of laborers and simplify administrative work, the labor department regards the latter and set a time limit of 48 hours, which is a reluctant action. Professor Dong Baohua points out that the fatal defect for the 48 hours clause is that it has no direct logical relation with overwork and the clause only underlines the disease place, rescue time but fails to form necessary causal relationship between right at rest, an antecedent right, and work-related injury compensation, a derivative right. ${ }^{4}$ The 48 hours clause forms stiff relation between the death caused by accumulated and sudden overwork, work time and rescue time, and the three conditions are considered necessary for identification of work-related injury, the legislative thinking is over-simple, and the clause has no adequate academic basis, and the administration just copies the rule in practice, there exist severe conflictions between simple rules and complicated situations of work-related injury in reality, which have finally caused the deviation of initial legal intention from the actual implementation effect. In the opinion of the author, the irrationality of the clause is embodied in three aspects:

First of all, it runs counter to the legislative spirit. According to Article 1 of the Regulations on Work-related injury Insurance it is clearly stipulated that "The regulations are formulated in order to enable employees who have suffered from work-related accidents or occupational diseases to obtain medical treatment and financial compensation", the three barriers of rescue time, work time and place have cause lots of laborers who fall sick from overtime or die but fail to completely meet the conditions cannot be deemed as workrelated injury, just like aforesaid Liu Hai, Zhang Zhijuan and $\mathrm{Xu}$ Dayong; yet those who die of disease at the work time and post but non-work reasons or die after rescue within 48 hours are qualified to enjoy the work-related injury compensation, seen from the two results, the defect of the 48 hours clause is obvious.

Second, it is inconformity to medical laws, individual differences in physique and health make the signs of individuals to the same diseases differ each other, besides, the differences in medical instruments and technical levels in hospitals cause different even opposite rescue results. Zheng Shanhai, associate chief physician of China Meitan General Hospital pointed out: Generally cerebrovascular disease cannot cause sudden death, and the most dangerous time is generally

${ }^{4}$ Dong Baohua, Exploring Laws Concerning Death from Overwork[J] Research on Rule of Law,2012(02) within about 72 hours after the disease attack. ${ }^{5}$ Yet, under a long term high pressure brainwork, $70 \%$ of death is caused by cardiovascular and cerebrovascular diseases... ${ }^{6}$ and it will be unfair to execute the "one size fits all" with the above factors ignored. Currently it is not difficult to maintain the patients with sudden diseases to live more than 48 hours through advanced medial technologies, obvious, the clause fails to match with current medical level.

Finally it will cause risks in ethic and morality. It's no doubt that the conditions of 48 hours and death for compensation induce family members of the patient and the employer to make adverse choices, as such, they are in an awkward situation to rescue the life or guarantee the compensation, it is extremely possible that the family members, under the economic pressure, regardless of the morality, will refuse the rescue so as to obtain the work-related injury compensation. Especially in the areas with undeveloped economy and rural areas where social insurance systems as basic medical insurance are imperfect, the work-related injury will be a life-saving straw for family members to obtain the economic subsidies from the state; ${ }^{7}$ and even the patients suffering from malignant diseases are induced to act on purpose as per the clause, and the diseases are induced to attack at the work time and post so as to gain the compensation through cheating. Similarly the employers may postpone the time through deceiving family members of patients, bribing doctors and even illegal ways so as to escape from the responsibilities. The law should be a powerful force to rectify social morality and purify social environment, yet the irrational conditions have pushed the family members and the employers to the forefront to violate public orders and social custom. When the rule brings challenges to the social morality, the value of the rule existing will be doubted.

\section{SugGestions to Improve the 48 Hours Clause}

Hegel pointed out that the integrity of a law was just an unceasing approach to the integrity. The innate lag of the law decides that it has to be supplemented as required. ${ }^{8}$ In order to follow the historical development of Chinese laws and maintain the stability of the laws, the 48 hours clause cannot be abolished or rebuilt simply, instead, we must abide by the legislative spirits and modify contents concerned on the basis of the clause. Besides, the modification shall be kept timely and prospective, with actual situations and potential factors considered, and adjusted as per social relations so as to fund the balancing point for the optimal benefits between the laborer, the employer and the society.

In order to improve the 48 hours clause, Qin Furong suggests that the restriction of 48 hours stated in the Regulations on Work-related Injury Insurance should be

\footnotetext{
${ }^{5}$ Yu Lisheng, Death After 48hous Not Contrary to Science and Ethic [J] Safety and Health, 2015(01)

${ }^{6}$ Wang Yue, The Status Quo of Death from Overwork Not deemed as WorkRelated Injury Should be Changed[N]. Health News, 2014-10-13/2016-8-20. 7 the same as 3

${ }^{8}$ Li Bifang, View on the Lack of Laws and Regulation concerning Death from Overwork in China [J]. Journal of Anhui Vocational College of Police Officers, 2011(06)
} 
cancelled; ${ }^{9} \mathrm{Ji}$ Guangzhao proposes that the rescue time should be pronged to 72 hours; ${ }^{10}$ Zhao Long thinks that the 48 hours should be deemed as rescue time only, excluding the hospital transfer time; ${ }^{11}$ Liu Desheng agues that the identification of work-related injury should depend on whether the rescue could change the death result but not be limited to the time whether the rescue could temporally prolong the death; ${ }^{12}$ Zhang Qun and Niu Zhongjiang suggest that if a patient sustains his or her life through breathing machines after rescue, it shall not be restricted by the 48 hours, and it shall be deemed as workrelated injury. ${ }^{13}$

If the limit of 48 hours is cancelled as what said by scholars above, it will cause the indefinite scope of work related injury, which go against the intention for modification by the labor departments; besides, regardless of 72 hours or 96 hours prolonged, some laborers will be out of the critical point, it still fails to solve the trouble of the clause in ethic, and the dispute will become increasingly fierce... In the opinion of the author, though the suggestions of scholars may buffer the contradictions temporarily, yet all fail to show the crucial reason, ignoring the key factor (work-related reason). The work-related injury refers to an accident injury that the laborer suffers from when working or dealing with work-related affairs. The Convention on Compensation for Agricultural Workers (No.12) approved in 1921 and the Convention on Allowances for Work-related Injury Incidents and Vocational Diseases (No.121) approved in 1961 by the International Labor Organization both defined the work related injury as "injury caused by work-related reasons". ${ }^{14}$ The key point for identification of work-related injury relies on the relation between sudden disease and work but not other factors as rescue.

The most direct cause for strong dissatisfactions by the society at the 48 hours clause is that a great number of laborers who die of overwork have occurred in recent years yet few are qualified for the work-related injury compensation. Most laborers find no legal support and feel difficult to protect the rights and interests of their own; meanwhile, the employers force employees to work under the loophole "not responsible for overwork". According to the Risk Formation Theory of Josserand, the incident occurs during the course of profit making, the employers, while making profits, should be

\footnotetext{
${ }^{9} \mathrm{Gu}$ Jian, Qin Furong, The Restriction of 48 Hours in the

Regulations on Work-related injury Insurance Should be Cancelled [EB/OL]. China News Center

http://news.china.com.cn/2014-03/11/content_31752190.htm 2014-311/2016-8-20

${ }^{10} \mathrm{Ji}$ Guangzhao, Ways to Break the Limit of 48 Hours for Work-Related Injury [J] Human Resources Development, 2013(12).

${ }^{11}$ Zhao Long, View on Rationality and Legal Feasibility of 48 Hours in the Regulations on Work-related injury Insurance [N]. Journal of Nanjing Party Institute of CPC,2015(06).

${ }^{12}$ Liu Desheng, How to Identify Work-Related Injury for Death after Rescue within 48 Hours [J]. Labor Security World 2009(05).

${ }^{13}$ Zhang Qun and Niu Zhongiang, View on Rationality and Ways to Improve the 48 Hours Clause in Regulations on Work-related injury Insurance [J]. China Labor,2009(11).

${ }^{14}$ Cai Gaoqiang, Zhang Junlian, Analyze the Improvement of Peasant Workers Social Security Systems from International Laborer Standard [J]. Hebei Law Science, 2006(03).
}

responsible for the risk but not for mistake. ${ }^{15}$ The nature of death from overwork is that the employer exerts laborers predatorily, which severely violate the rights of rest and lift of the laborers. Acting as the final beneficiary, it is a must for the employer to take responsibilities.

Up to now, the death from overwork is still not defined in laws in China and no relevant protective rules are established. It is urgent to improve the systems, and only the law could take the mission. Professor Wang Quanxing thinks that the death from overwork and the work-related injury are the same in nature, both of the death of laborers are caused by the employers which violate the obligations to protect the safety and health of laborers, which can be considered as a special form of work-related injury. ${ }^{16}$ Professor Peng Guanghua also thinks that the death from overwork has one or two characteristics, so it should be taken as a special form of workrelated injury. ${ }^{17}$ The author agrees on opinions of the two scholars mentioned above, due to the uncertain time and place, the death from overwork cannot meet the 48 hours clause completely, yet the declination of physical functions of laborers under a long term overwork, falling sick from overwork and even death all are caused by the work, the nature of such incidents are consistent with the spirit of work-related injury insurance. Based on the objective conditions in practice and appeals for legislation, the author suggests that the death from overwork can be introduced through expanding the extension to improve the 48 hours clause, which can not only solve the irreparable defect in theory but also incorporate the death from overwork into the identification of work-related injury with the time going.

However, to incorporate the "death from overwork" for amending the clause cannot be accomplished in an action. The key is how to quantify the "over higher work intensity" into specific operational standards. In the opinion of the author, it can be achieved through three-step strategy.

Step I, cancel the rescue time limit and add the limit of "work-related reasons", namely it's amended as: "the death of sudden diseases at the work time, post or work-related reasons or death after rescue, will be deem as work-related injury, and the work-related reasons shall be defined by laws and regulation, which will initially expand the proportion of the patients dying of overwork in the work-related injury system and buffer social contradictions caused by the original clause.

Step II, remove the limit in time and place as required in "work time and post", and it is amended as: "Death of sudden disease due to work or death after rescue shall be deemed as the work-related injury, the work-related reasons shall be defined by laws and regulations.

Step III, adjust the work-related injury compensation system, incorporate the not dying of sudden diseases but

\footnotetext{
${ }^{15}$ Cao Qiaochun, Study on Responsibilities for Work-Related Injury Compensation [M], Beijing; Law Press, 2011:49.

${ }^{16}$ Wang Quanxing, Guan Bin, Legal Thoughts about Death from Overwork [J]. Lawyer World,2001(05)

${ }^{17}$ Cai Gaoqiang, Zhang Junlian, Analyze the Improvement of Peasant Workers Social Security Systems from International Laborer Standard [J]. Hebei Law Science, 2006(03).
} 
"Diseases due to overwork" of laborers in the work-related injury with the labor capacity identified so as to determine the injury level for appropriate compensation. It is amended as: "Dying of sudden diseases or dying after rescue due to workrelated reasons, is deemed as work-related injury, if not dying, the laborer shall have his or her labor capacity level identified for compensation, and the work-related reasons shall be defined by laws and regulations.

As for the overwork standards stipulated in laws and regulations, the state should set up a team of experts covering a wide range of disciplines, borrow the advanced experience of Japan and so on in the "death from overwork" practice and consider the existing fatigue research results (as Xue Xiaolin proposes fatigue self measuring sheet meeting the situations in China from fatigue expression, degree and characteristics ${ }^{18}$ ) to establish overwork standards suitable for all fields in China and update regularly, meanwhile, the administrative practice should be combined with additional factors as work environment for scientific judgment.

Pathogenic factor of sudden disease are complex, in order to determine the main reason, the author suggests that the principle of proximate cause used in insurance can be borrowed. The proximate cause in the insurance means that based on judging the causal relationship between incident and damage result, determine the reasons to compensate or not, but not on reasons nearest in time. The administrative department for identification of work-related injury should list all reasons as more as possible, and finds out the key reasons according to the physical examination, medical records, part-time job and so on. If the proximate cause is clear, besides, the overwork in the employer is a proximate cause for the disease attack or death, there is no doubt it shall be deemed as work-related injury, otherwise it may be not; if the proximate cause is vague, namely both the work-related reasons and non-work related reasons will cause death, following the principle to protect the laborers, it shall be deemed as work-elated injury

\section{CONCLUSION}

The construction of any system has advantages and disadvantages, there are no impeccable systems and no theories not needing improvement. ${ }^{19}$ The current 48 hours clause, in the lack of scientific basis, misinterprets the purpose of the Regulations on Work-related Injury Insurance; the cases of death from overwork occur frequently, which has become a serious problem for the labor department to face. With the 48 hours clause modified, the death from overwork is incorporated in the work-related injury system. With the basic status of the work-related reasons for the identification of work-related injury, it not only removes the embarrassment at the time node, but also solves the dispute and conforms to the situation of the time. It has considered both the actual needs and the legislative spirit, and fully reflected the improvement of legislative quality and level in the country.

\footnotetext{
${ }^{18}$ Lin Jia, Concept, Practice and Innovation of Social Security Law, Beijing, China Renmin University Press, 2002

${ }^{19}$ Sun Shuhan, Work-Related Insurance, China Labor and Social Security Publishing House, $[\mathrm{M}], 2007$
}

\section{REFERENCES}

[1] Liu Hai, engineer in a Shenzhen-stationed company, suffered from a sudden disease in the company but died after rescuing for 77 hours, within three months before death his overwork time were 93, 82.5 and 128 hours respectively. According to the rescue time which exceeded 48 hours, Shenzhen Human Resources and Social Security Administration identified it as non-work-related injury; Yan Zhaoxiong, engineer, suffered from heart attack at work, the rescue time reached 77 hours, he was not identified as work-related injury [EB/OB] Shenzhen Evening News. http://news.sina.com.cn/s/2011-03-25/170322181896.shtml 2011-3-25/2016-8-20

[2] Zhang Zhijuan, street cleaner, working overtime often in 20 years, Harbin. After working 4 hours before dawn on Feb 14, she started an 8 hour work from the morning, when working, she suffered from a sudden cerebral hemorrhage and became a gork after rescue. Surprisingly her employer said: it's not deemed as work-related injury for she's alive as provide in the law; A model street cleaner suffering from a disease at work has no money for treatment, the employer said: it's not deemed as work-related injury for she's alive [EB/OL] Yangcheng Evening News. http://www.ycwb.com/ePaper/ycwb/html/2012-

05/17/content_1392947.html 2012-5-17/2016-8-20

[3] $\mathrm{Xu}$ Dayong, an employee in a company, Jiangsu province, worked in the burning sun during Jul 16-18 and was on duty for two nights. In the afternoon of Jul 18, he felt uncomfortable and got off work at 19 p.m. In the early morning, his disease worsened and died in the morning of Jul 19 after rescue in a hospital. He was diagnosed with brainstem hemorrhage, yet the labor department considered that $\mathrm{Xu}$ Dayong suffered from a sudden disease at home, which was inconformity with the identification of work-related injury "disease at work and work place", so it was not deemed as work-related injury; Wang Chengyu and Li Linqing, Conditions and Identification for Death Deemed as WorkRelated Injury [EB/OL] People's Court Daily (Vision VII). http://www.chinacourt.org/article/detail/2015/03/id/1573875.shtml 2015-3-26/2016-8-20

[4] Dong Baohua, Exploring Laws Concerning Death from Overwork[J] Research on Rule of Law,2012(02)

[5] Yu Lisheng, Death After 48hous Not Contrary to Science and Ethic [J] Safety and Health, 2015(01)

[6] Wang Yue, The Status Quo of Death from Overwork Not deemed as Work-Related Injury Should be Changed[N]. Health News, 2014-1013/2016-8-20

[7] The same as 3

[8] Li Bifang, View on the Lack of Laws and Regulation concerning Death from Overwork in China [J]. Journal of Anhui Vocational College of Police Officers, 2011(06).

[9] Gu Jian, Qin Furong, The Restriction of 48 Hours in the Regulations on Work-related injury Insurance Should be Cancelled [EB/OL]. China News Center. http://news.china.com.cn/201403/11/content_31752190.htm 2014-3-11/2016-8-20

[10] Ji Guangzhao, Ways to Break the Limit of 48 Hours for Work-Related Injury [J] Human Resources Development, 2013(12).

[11] Zhao Long, View on Rationality and Legal Feasibility of 48 Hours in the Regulations on Work-related injury Insurance $[\mathrm{N}]$. Journal of Nanjing Party Institute of CPC,2015(06).

[12] Liu Desheng, How to Identify Work-Related Injury for Death after Rescue within 48 Hours [J]. Labor Security World 2009(05).

[13] Zhang Qun and Niu Zhongjiang, View on Rationality and Ways to Improve the 48 Hours Clause in Regulations on Work-related injury Insurance [J]. China Labor,2009(11).

[14] Cai Gaoqiang, Zhang Junlian, Analyze the Improvement of Peasant Workers Social Security Systems from International Laborer Standard [J]. Hebei Law Science, 2006(03).

[15] Cao Qiaochun, Study on Responsibilities for Work-Related Injury Compensation [M], Beijing; Law Press, 2011:49

[16] Wang Quanxing, Guan Bin, Legal Thoughts about Death from Overwork [J]. Lawyer World,2001(05):10-11 
[17] Cai Gaoqiang, Zhang Junlian, Analyze the Improvement of Peasant Workers Social Security Systems from International Laborer Standard [J]. Hebei Law Science, 2006(03).

[18] Lin Jia, Concept, Practice and Innovation of Social Security Law, Beijing, China Renmin University Press, 2002

[19] Sun Shuhan, Work-Related Insurance, China Labor and Social Security Publishing House, $[\mathrm{M}], 2007$. 